\title{
PROJEKTIMI I LOGJIKËS FUZZY DHE RREGULLATORIT PID NË PROCESET INDUSTRIALE Jozef Kola*, Serxho Langa**
}

*Departamenti i Inxhinierive, Fakulteti i Shkencave të Aplikuara dhe Ekonomike,

\author{
Albanian University \\ Adresë kontakti: j.kola@albanianuniversity.edu.al
}

\section{Përmbledhje}

Proceset industriale po ndërlikohen ditaditës, duke prezantuar modele të paqëndrueshme të rendit më të lartë. Rregullatori i derivatit integral proporcional (PID) është metoda e kontrollit më e përdorur në industri, për shkak të performancës së lartë dhe gamës së gjerë të kushteve të funksionimit dhe mwnyrat e thjeshta të rregullimit.

Ky punim paraqet projektimin e rregullatorit PID duke përdorur teknikën Ziegler - Nichols $(\mathrm{ZN})$, metoda për kontrollin e sistemit të rendit më të lartë. Për të njëjtin qëllim, do të përdoret edhe logjika Fuzzy (FLC) duke përdorur rregulla më të thjeshta.

Rezultatet e simulimit demostrohen duke përdorur MATLAB. Analiza e performancës tregon efektivitetin e projektuar të logjikës Fuzzy, krahasuar me rregullatorin PID të akorduar me ZN.

Fjalë çelës: kontroll procesi, PID, logjika Fuzzy.

\section{SIMPLIFIED FUZZY LOGIC AND PID CONTROLLER DESIGN FOR INDUSTRI-}

\section{AL PROCESSES}

\begin{abstract}
Several industrial processes are getting complicated day by day introducing an unstable higher order model. The proportional integral derivative (PID) controller is the most widely used control strategy in industry, due to their robust performance in a wide range of
\end{abstract}


Jozef Kola, Serxho Langa

operating conditions and their simple tuning methods. This paper presents the design of PID controller using Ziegler - Nichols (ZN) tuning technique for controlling the higher order system. For the same purpose, a Fuzzy logic controller (FLC) using smaller rule set is proposed. Simulation results are demonstrated using MATLAB. Performance analysis shows the effectiveness of the designed Fuzzy logic controller as compared to the ZN tuned PID controller.

Keywords: Process control, PID, Fuzzy logic.

\section{Hyrje}

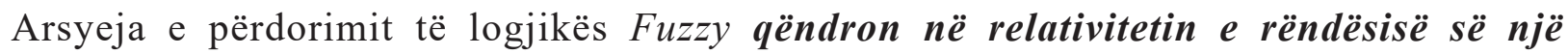
përgjigjeje ekzakte: "Sa e rëndësishme është të marrësh një përgjigje ekzaktësisht të saktë, kur mund të nevojitet një përgjigje e përgjithshme?"

Edhe pse logjika fuzzy është metodë e re, koncepti i aplikimit të saj bazohet në arsyetimin e njeriut, që është një aftësi e hershme.

Objektivi kryesor i këtij punimi është studimi i sistemit të rendit të tretë me PID dhe logjikën Fuzzy.

Në punim trajtohen metodat e përpunuara të marra nga konsultimi i literaturës, si dhe bëhet përpjekje për të rritur saktësinë e rezultateve të tyre duke i kombinuar me metodat dhe teoritë e reja të përpunimit të të dhënave siç është logjika Fuzzy.

\section{Një pershkrim i përgjithshem i logjikës Fuzzy}

Eshtë dëshmuar se aftësitë e njeriut për të kontrolluar raste të tilla të komplikuara kanë dalë të suksesshme dhe më të frytshme, sidomos kur ato vendime mbështeten në përvojën e operatorëve të problemit konkret. Aplikimi i teknikave të inteligjencës artificiale dhe sidomos të Sistemeve Eksperte të vendimmarrjes, ka mundësuar që këto përvoja të barten në algoritmin e kontrollit. Këto janë teknika kompjuterike, të cilat tentojnë të bartin tek makina, mënyrën njerëzore të të menduarit dhe vendimmarrjes. Për procesin e vendimmarrjes ato nuk ndjekin procedura të zakonshme të programimit konvencional, por, rezonojnë bazuar në përvoë, tamam si një ekspert njerëzor, i cili ka përvojë me atë sistem. Në shumicën e rasteve, këto teknika nuk i zëvendësojnë plotësisht teknikat konvencionale të kontrollit, por i përmirësojnë rezultatet duke u zbatuar paralelisht ose duke u integruar me to.Një teknikë shumë e suksesshme e Sistemeve Eksperte është logjika Fuzzy. Elementi kryesor që sjell aplikimi i logjikës Fuzzy është se, qasja fuzzy logjike arrin që të implementojë tek logjika e kontrollit, përvojën ë ka operatori i kontrollit, e cila shprehet përmes vlerave gjuhësore jo shumë precize, duke e kthyer atë në një algoritëm numerik. Të gjitha ato panjohuri dhe paqartësi në 
PROJEKTIMI I LOGJIKËS FUZZY DHE RREGULLATORIT PID NË PROCESET INDUSTRIALE

lidhje me sistemit e kontrollit FLC, arrijnë të eliminojnë mbirregullimin dhe kohën e rregullimit dhe është e frytshme, sidomos për rastet e devijimeve ekstreme, duke shkurtuar kohën e stabilizimit të sistemit. Njëri nga problemet kryesore të kontrollit Fuzzy logjik është përshtatja e koeficientëve të tyre, sepse nuk ka ndonjë rregullore si rrugërrëfim për mënyrën e zgjedhjes dhe përshtatjes së tyre [1].

\section{3. Çfarë është logjika Fuzzy?}

Logjika Fuzzy ka dy kuptime të ndryshme. Në një këndvështrim të ngushtë është një sistem logjik. Në një kuptim më të gjerë është sinonimi i teorisë së grupeve Fuzzy, e cila u referohet bashkësive të objekteve që kanë kufij të papërcaktuar, dhe të qenit pjesë e këtyre bashkësive përcaktohet në nivele sasiore në përqindje. Pra, një element mund të jetë pjesë e një bashkësie, pjesërisht mund të shmanget vlerësimi, është plotësisht apo s'është fare. Këtë e shpreh teoria Fuzzy. Dhe në kuptimin e parë, logjika Fuzzy ndryshon në koncept dhe në substancë me sistemet logjike tradicionale. Në këtë studim, logjika Fuzzy do të studiohet në raport me teorinë e grupeve Fuzzy.

Kjo logjikë ka si veçanti përdorimin e variablave linguistikë, të cilët kanë si vlera apo parametra fjalët dhe jo numrat.

Kjo metodë përdor për llogaritje fjalët dhe jo numrat. Edhe pse fjalët janë më pak të sakta se numrat, përdorimi i tyre qëndron më afër intuitës njerëzore. Një veçanti në përdorimin e logjikës Fuzzy është përdorimi i rregullave Fuzzy. Ato janë të ndërtuara në formën "nëse atëherë”. Sistemet e bazuara në rregulla kanë gjetur përdorim të gjerë në Inteligjencën Artificiale, por ajo që u mungon këtyre sistemeve është një mekanizëm që bën lidhjen e shkakut me pasojën. Ky lloj mekanizmi është ndërtuar në sistemin fuzzy. Ky mekanizëm quhet Varësia Fuzzy dhe Gjuha e Komandës (FDCL - Fuzzy Dependency and Command Language).

Arsyeja e përdorimit të logjikës Fuzzy qëndron në relativitetin e rëndësisë së një përgjigjeje ekzakte: “Sa e rëndësishme është të marrësh një përgjigje ekzaktësisht të saktë, kur mund të nevojitet një përgjigje e përgjithshme?” Edhe pse logjika Fuzzy është metodë e re, koncepti i aplikimit të saj bazohet në arsyetimin e njeriut, që është një aftësi e hershme. Parë në këtë këndvështrim, logjika Fuzzy mund të konsiderohet metodë e re dhe e vjetër. Në logjikën Fuzzy vihet në balancë saktësia dhe kuptimi i përgjithshëm i një përgjigje [1]. 
Jozef Kola, Serxho Langa

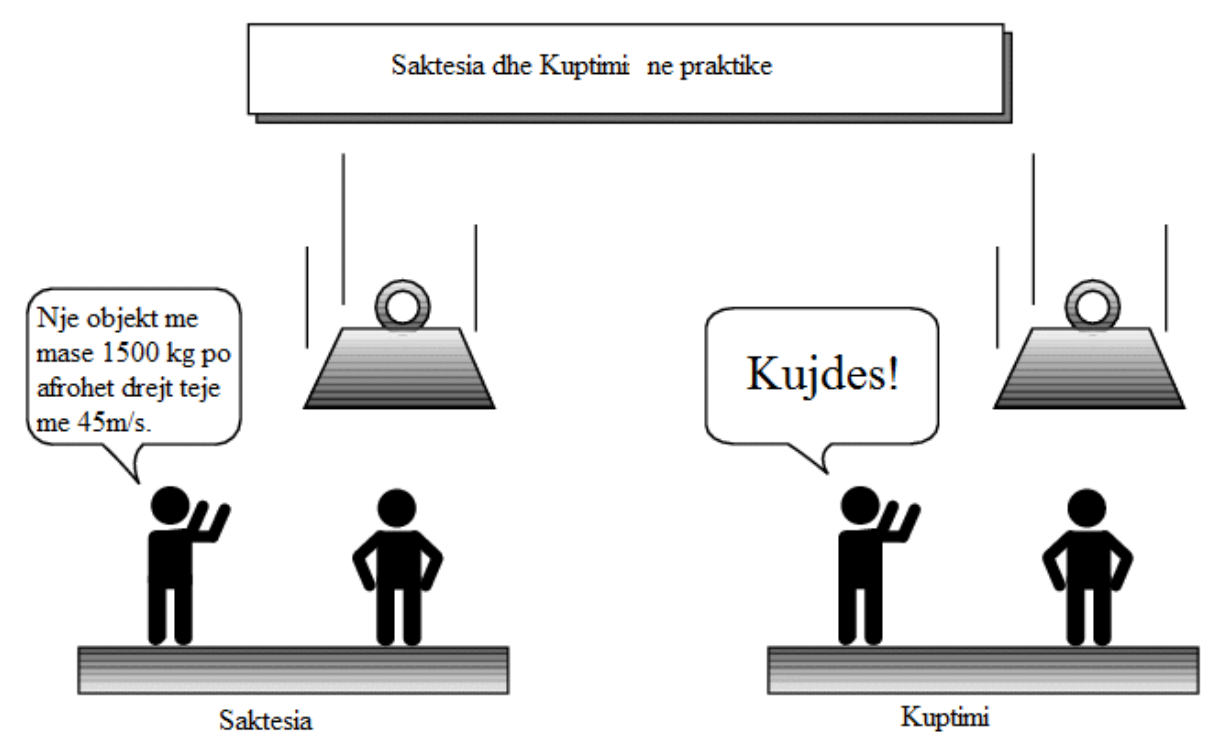

Figura 1: Në logjikën Fuzzy vihet në balancë saktësia dhe kuptimi i përgjithshëm i një përgjigje

\section{Përdorimi i logjikës Fuzzy}

Më poshtë është renditur një listë me vlerësimet që i janë bërë logjikës Fuzzy:

○ Konceptet themelore të këtij sistemi janë të lehta për t'u kuptuar. Arsyetimi që ndjek kjo metodë bazohet në koncepte të thjeshta matematikore,

○ Logjika Fuzzy është fleksibël si sistem. Mund të bashkëveprojë me lehtësi me sistemet e tjera,

○ Është sistem tolerues ndaj të dhënave që kanë një shkallë pasaktësie,

○ Logjika Fuzzy mund të modelojë funksione jolineare me shkallë të lartë kompleksiteti,

○ Mund të ndërtohet një sistem Fuzzy që mund të funksionojë me çdo lloj të dhënash si inpute dhe outpute,

○ Një sistem Fuzzy mund të ndërtohet duke u bazuar në njohuritë e ekspertit të fushës,

○ Logjika Fuzzy mund të punojë në harmoni të plotë me teknikat tradicionale të kontrollit. Këto të fundit, duke u shtuar logjikën Fuzzy, bëhen më të lehta për t'u zbatuar,

○ Përdorimi i logjikës Fuzzy bazohet në gjuhën e thjeshtë të komunikimit. Kjo e bën këtë sistem të lehtë për t'u përdorur.

Vlerësimi i fundit i bërë ndaj sistemit Fuzzy është më i rëndësishmi [1]. 
PROJEKTIMI I LOGJIKËS FUZZY DHE RREGULLATORIT PID NË PROCESET INDUSTRIALE

\section{Relacionet linguistike (Rregulla Fuzzy të tipit «nëse - atëherë»)}

Relacionet linguistike janë rregulla logjike që përdoren për të kryer veprime dhe për të lidhur elementët e ndryshëm të bashkësive Fuzzy, për të arritur në një gjykim final.

"nëse $x$ është A, atëherë y është $B$

$k u x$ dhe y janë dy elemente të universit të diskutimit $X$ dhe $Y$ respektivisht, ndërsa $A$ dhe $B$ janë vlerat linguistike me anë të të cilave u referohemi dy bashkësive Fuzzy në universet e diskutimit $X$ dhe $Y$ respektivisht."

Pjesa e majtë e relacionit është quajtur paraardhësja ose premisa, ajo e djathta konsekuenca ose konkluzioni. Ato mund të quhen gjithashtu shkaku dhe pasoja.

Një relacion linguistik nuk është gjë tjetër veçse bashkim i një shprehje linguistike hyrje me një shprehje linguistike dalje. Në përgjithësi, hyrja e një relacioni linguistik është vlera aktuale e një variabli të hyrjes, ndërsa dalja është një bashkësi e plotë Fuzzy. Kjo bashkësi e plotë Fuzzy do të jetë kthyer në një vlerë numerike të vetme, me anë të të ashtuquajturit defuzifikim.

Interpretimi i një rregulli përfshin pra, dy pjesë të dallueshme: vlerësimin e premisës, që përfshin fuzifikimin e hyrjes dhe aplikimin e operatorëve Fuzzy, si dhe marrjen e rezultatit si konsekuencë, veprim i shënuar si implikim. Në logjikën binare, aplikimi i një rregulle nuk paraqet ndonjë vështirësi: nëse premisa është e vërtetë, konkluzioni është i vërtetë.

Aplikimi i së njëjtës rregull, tek logjika fuzzy, nënkupton që nëse premisa është e vërtetë sipas një shkalle përcaktuese të vërtetësisë, atëherë konkluzioni është i vërtetë me të njëjtën shkallë vërtetësie.

Premisa e një rregulle (kështu dhe konsekuentja) mund të jetë përbërë nga më shumë pjesë: -nëse $x$ është $A$ dhe $y$ është $B$, atëherë $z$ është $C$ (2 premisa dhe 1 konsekuencë), -nëse $x$ është $A$, atëherë $y$ është $B$ dhe $z$ është $C$ (1 premise dhe 2 konsekuenca), Në një rast të tillë, secila pjesë e premisës është vlerësuar në mënyrë individuale [2].

\section{Funksionimi i sistemeve Fuzzy}

Siç është parë në paragrafët e mëparshëm, një sistem Fuzzy është karakterizuar nga elementet e mëposhtme:

○ funksioni i anëtarësisë së hyrjes,

- rregulla fuzzy,

○ funksioni i anëtarësisë së daljes.

Pas përcaktimit të një sistemi të tillë, çështja qëndron se si do ta përdorim këtë sistem, si do ta vëmë atë në funksionim. Çfarë rrugësh dhe metodash do të përdoren për të analizuar tërësinë e informacionit në hyrje të këtij sistemi, me qëllim që të kemi një rezultat logjik të vetëm mbi të cilin do të mbështetet vendimmarrja. 
Jozef Kola, Serxho Langa

Duke përdorur këto elemente dhe vetitë e tyre proceset dhe veprimet në një sistem Fuzzy do të kalojnë në disa faza të renditura si më poshtë:

- Fuzifikimin e hyrjeve,

- Inferenza (gjykimi) Fuzzy,

- Kompozimi i daljes Fuzzy,

- Defuzifikimi [2].

\section{Simulim në Matlab - Sistemi i rendit të tretë me PID dhe logjikën Fuzzy}

Modeli i simuluar i rregullatorit PID duke përdorur teknikën e ZN është paraqitur në Fig. 2 [3]. Funksioni transmetues është i rendit të tretë me tre pole, kur polet nxirren duke barazuar emëruesin me zero, dhe numri i zerove të fuksionit është zero [3].

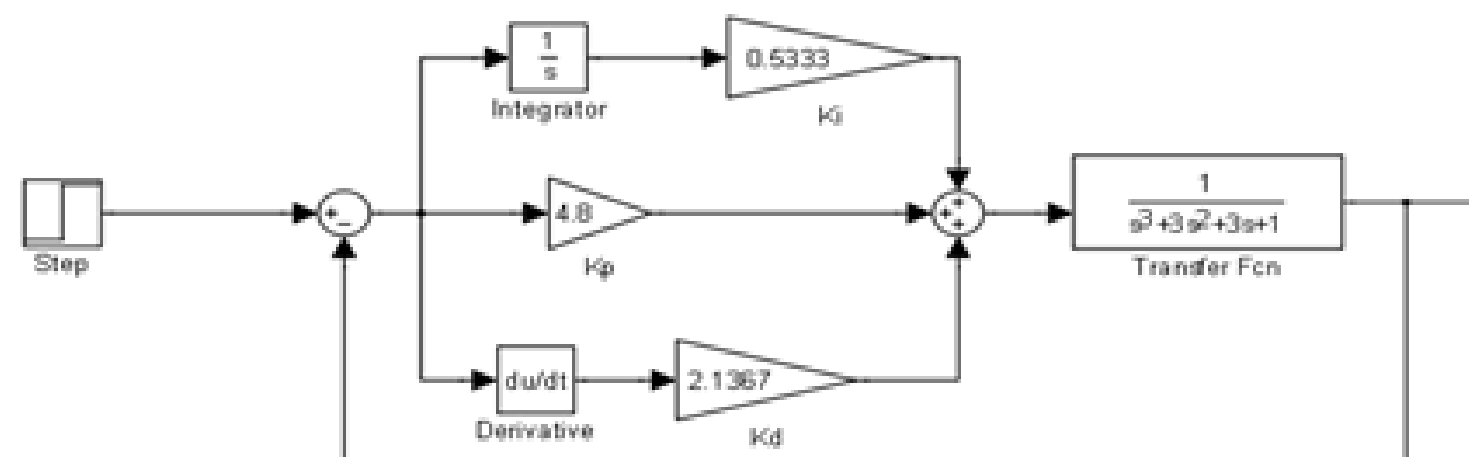

Figura 2: Simulimi në Matlab i rregullatorit PID

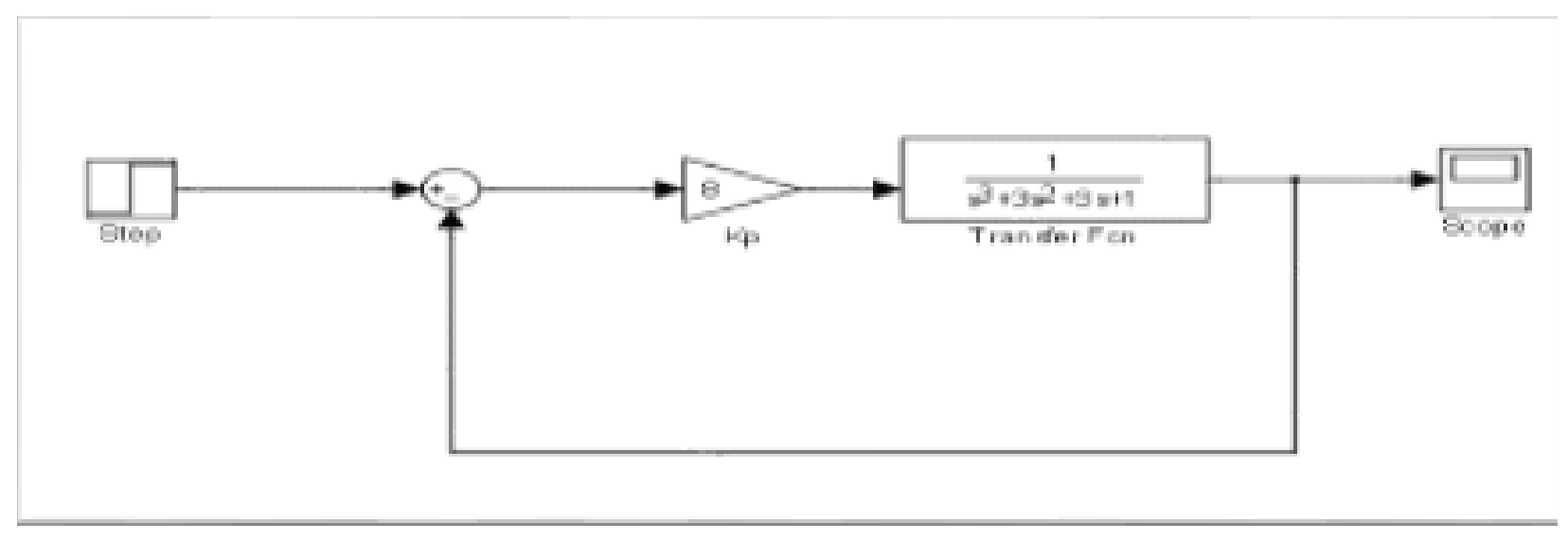

Figura 3: Funksioni transmetues i procesit

Për vlera të koeficentit $\mathrm{K}_{\mathrm{p}}=8, \mathrm{~T}_{\mathrm{i}}=\infty$ dhe $\mathrm{T}_{\mathrm{d}}=0$ kemi ndërtuar përgjigjen kalimtare si më poshtë. 


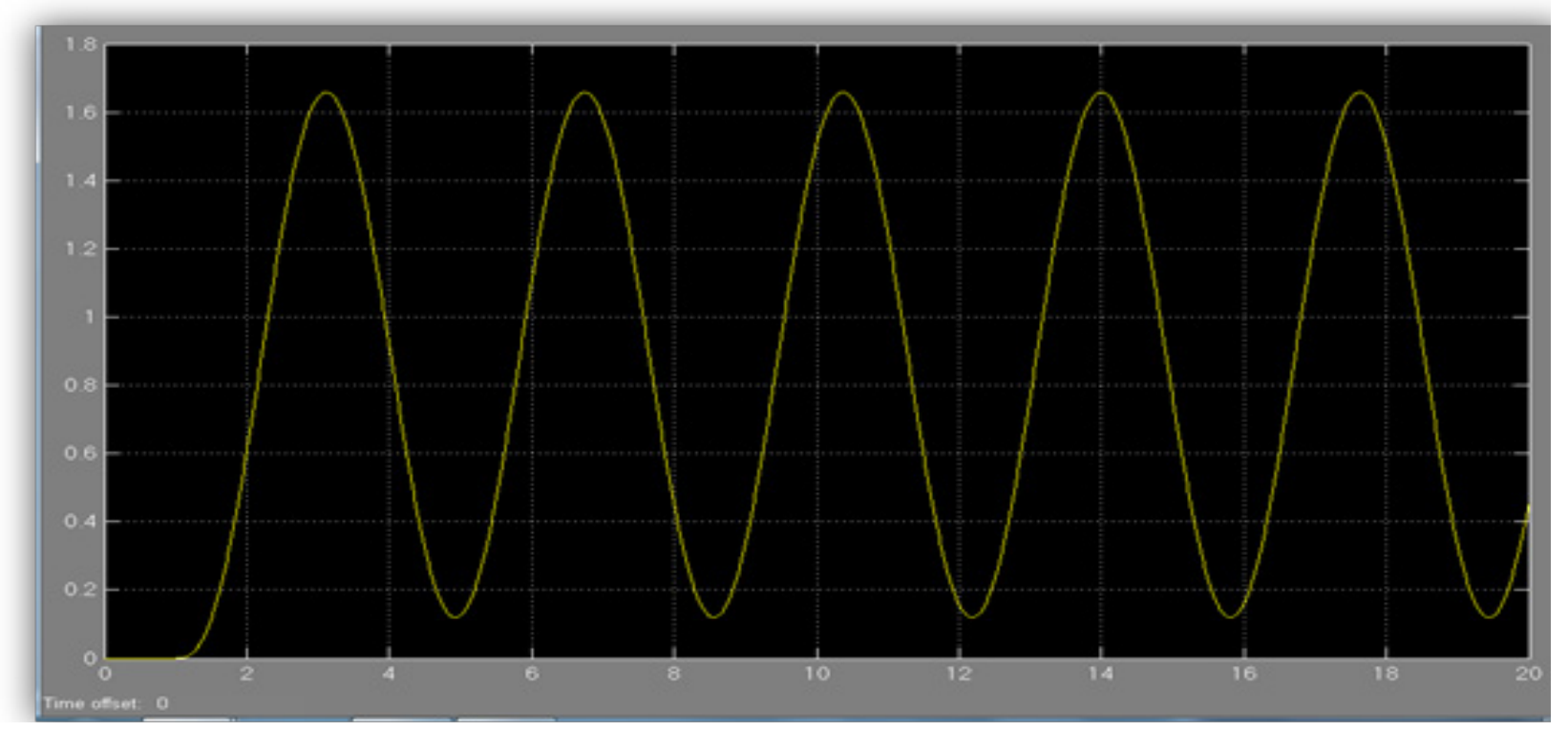

Figura 4: Përgjigjia kalimtare e procesit industrial

Pasi kemi ndërturpërgjigjen kalimtare për $\mathrm{K}_{\mathrm{p}}=8$ bejmë simulimin në Matlab duke futur rregullatorin PID, së bashku me koeficientët përkatës. Në varësi të simulimit në Matlab për koeficientin $\mathrm{K}_{\mathrm{p}}=4.8, \mathrm{~T}_{\mathrm{i}}=1.875$ dhe $\mathrm{T}_{\mathrm{d}}=0.468$ dhe nga konstantet e kohës $\mathrm{T}_{\mathrm{i}}$ dhe $\mathrm{T}_{\mathrm{d}}$ nxjerrim koeficientin përkatës duke $u$ bazuar në formulën $K_{i}=1 / T_{i}, K_{d}=1 / T_{d}$. Për këto të dhëna ndërtojmë përgjigjen kalimtare.

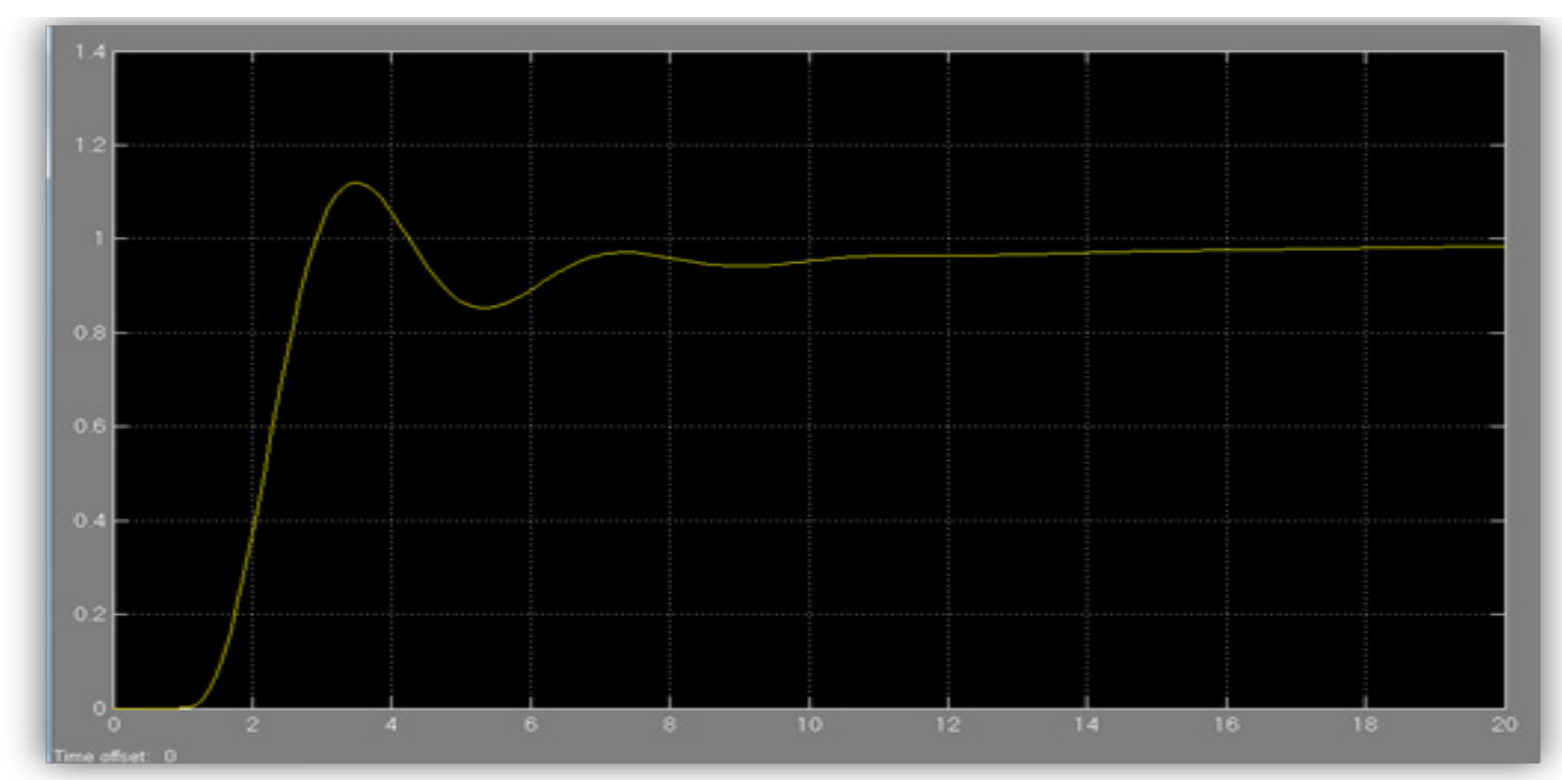

Figura 5:Përgjigjia kalimtare e sistemit me PID

Revistë shkencore e "Albanian University" 
Jozef Kola, Serxho Langa

Nga pergjigjia kalimtare marrim parametrat e cilwsisë, të cilët janë mbirregullimi $49.24 \%$ dhe kohën e rregullimit, e cila është 8.83 sekonda.

Projektimi, ndërtimi dhe simulimi i sistemeve Fuzzy logjike bazohet ne katër hapa elementare:

1. Definimi i hyrjeve dhe daljeve (INPUTS dhe OUTPUTS),

2. Krijimi i dhe definimi i funksioneve të antarësisë (Membership Functions),

3. Krijimi i rregullave (Rules),

4. Simulimi i sistemit Fuzzy - logic rezultues [4].

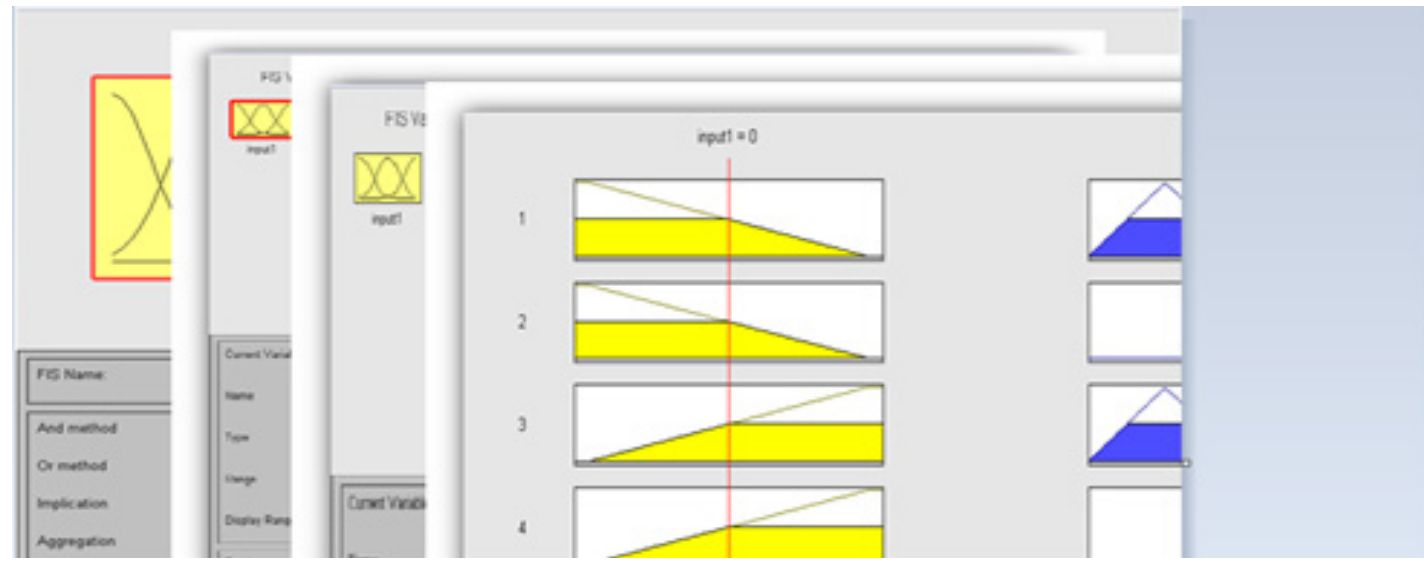

Figura 6: Ndërfaqet e logjikës Fuzzy

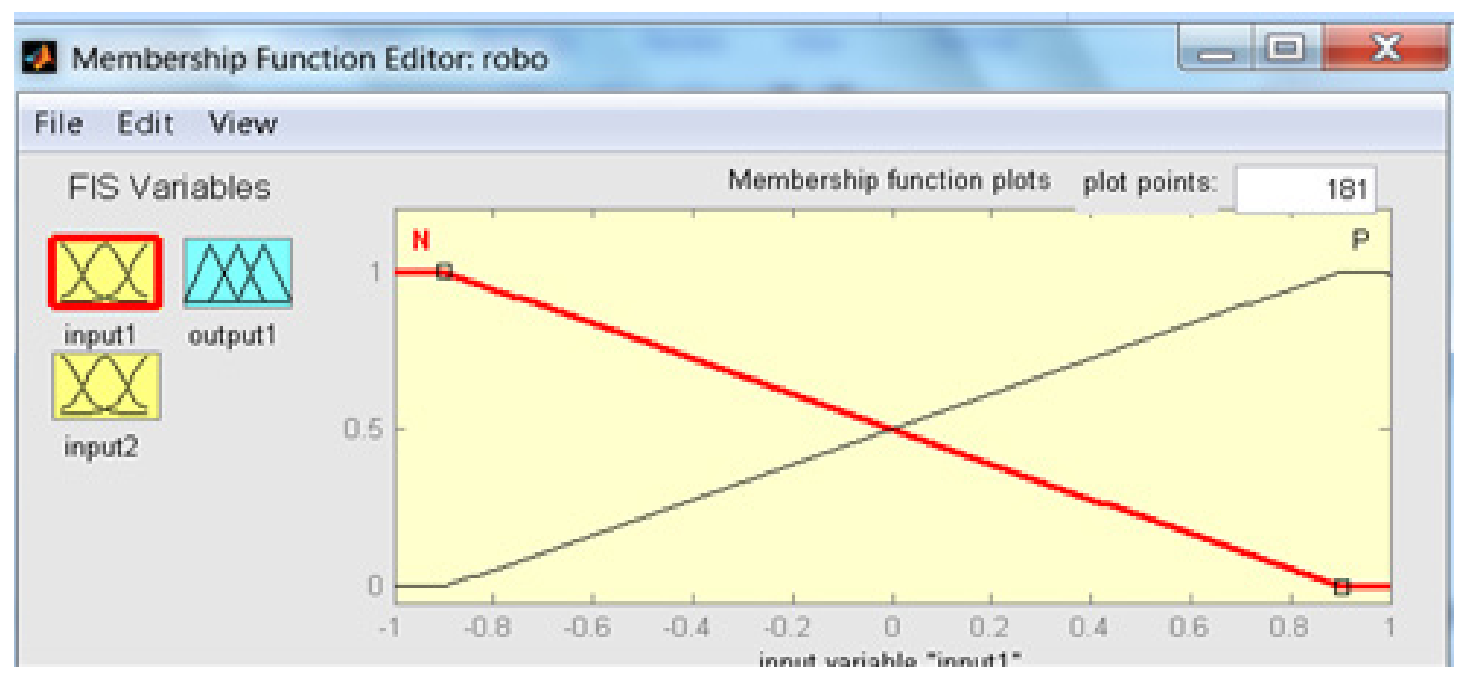

Figura 7: Përcaktimi i variablave të hyrjes 
PROJEKTIMI I LOGJIKËS FUZZY DHE RREGULLATORIT PID NË PROCESET INDUSTRIALE

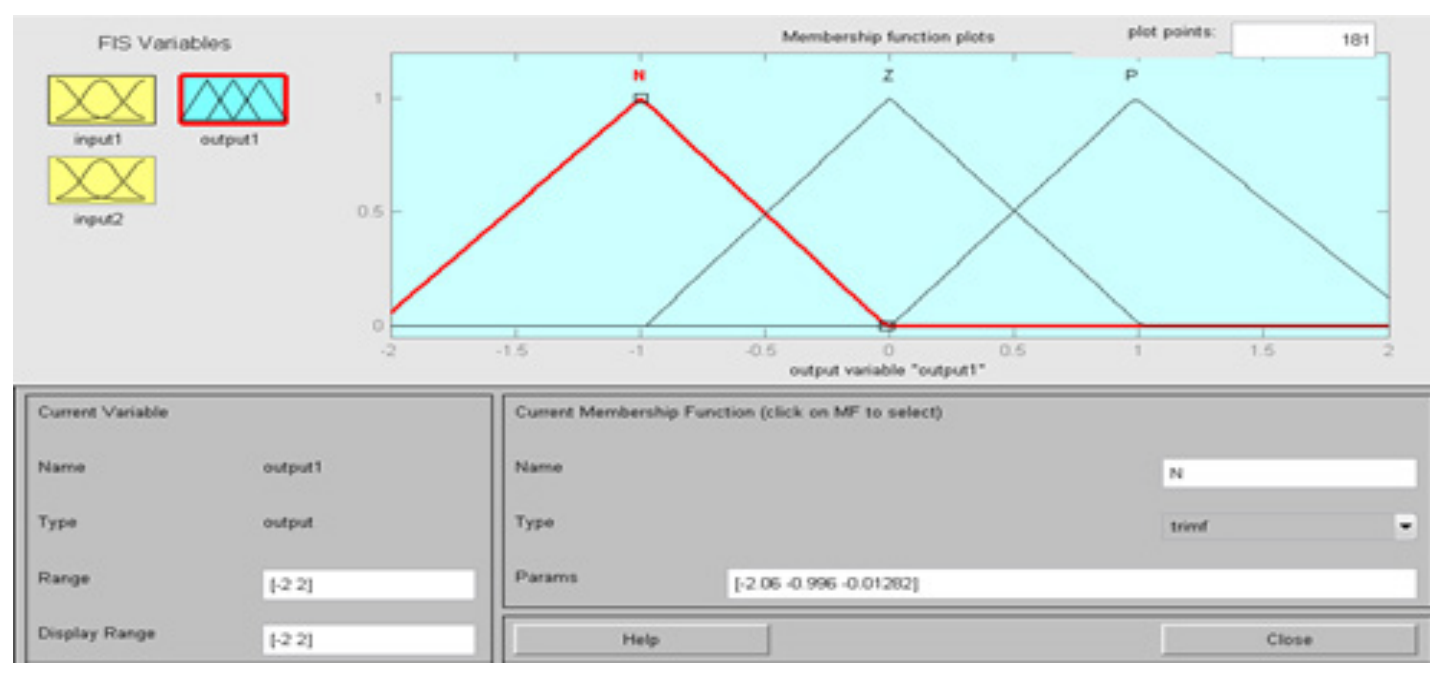

Figura 8: Përcaktimi i variablave të dalje

Vendosen rregullat përmes të cilave do të definojmë sjelljen e sistemit tonë.

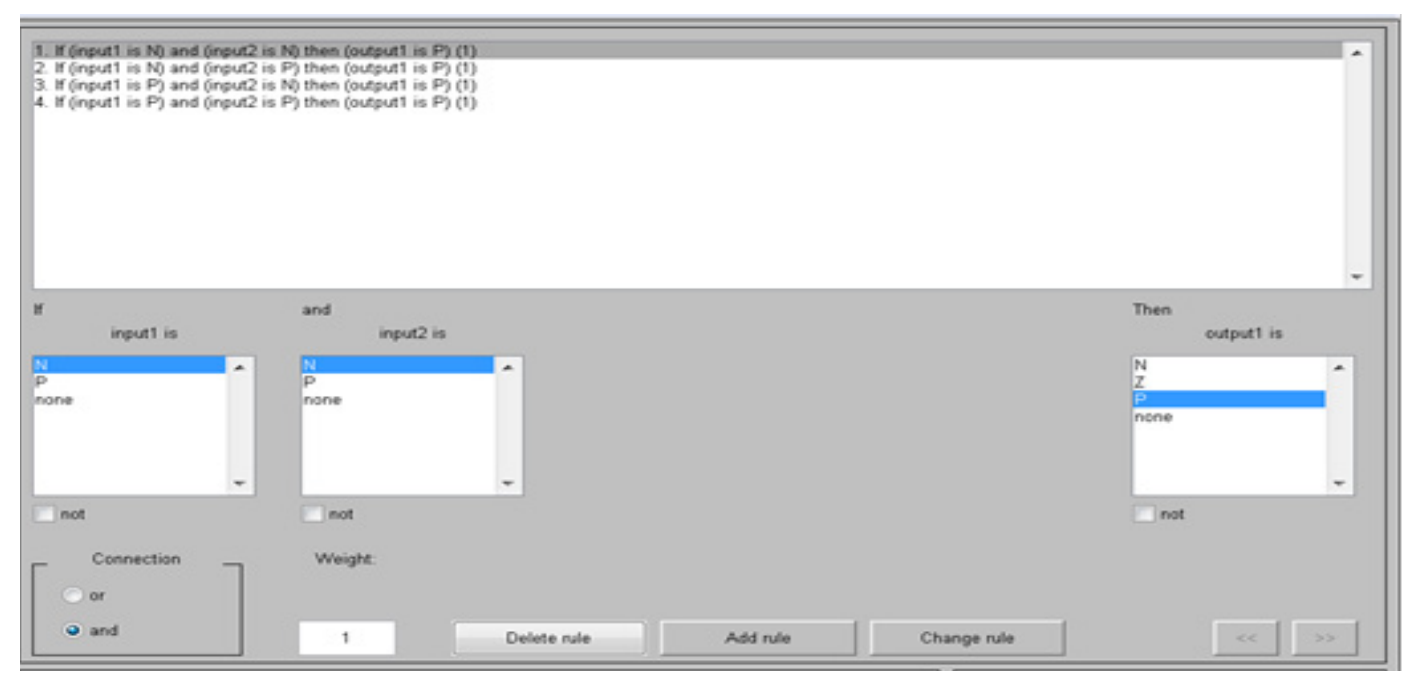

Figura 9:Rregullat e logjikës Fuzzy 
Jozef Kola, Serxho Langa

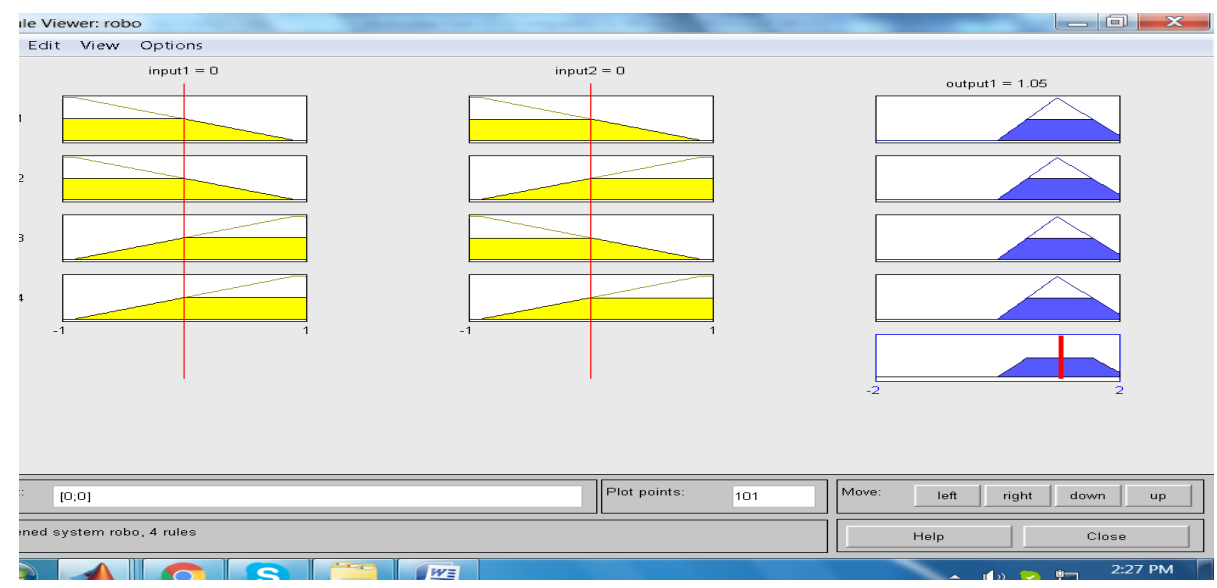

Figura 10:Përcaktimi i hyrjeve dhe daljeve

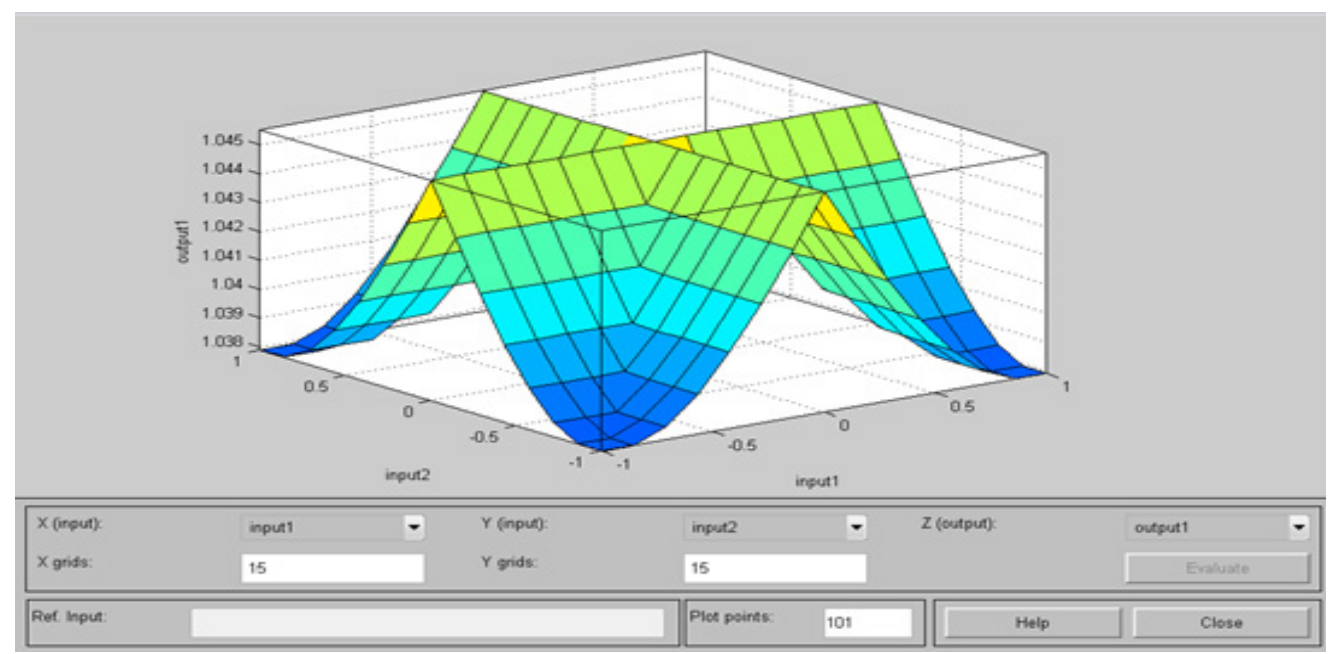

Figura 11:Paraqitja 'surface' e daljeve

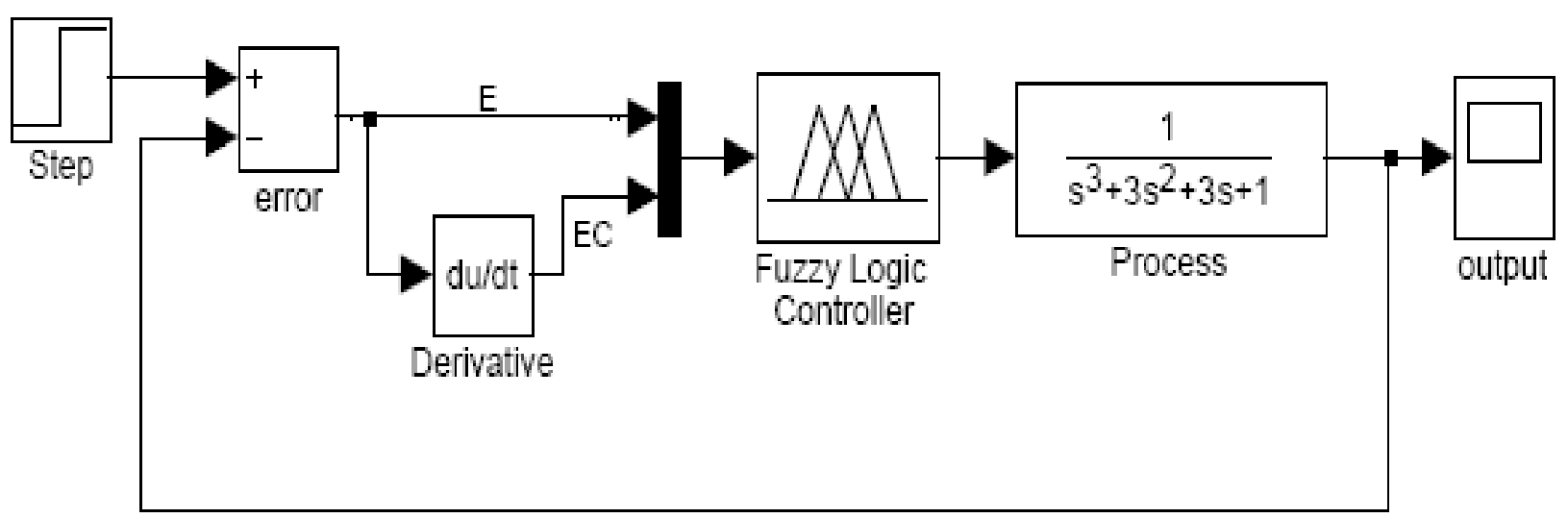

Figura 12:Simulimi ne Matlab i logjikës Fuzzy për procesin 
PROJEKTIMI I LOGJIKËS FUZZY DHE RREGULLATORIT PID NË PROCESET INDUSTRIALE

Pasi kemi percaktuar rregullat dhe kemi ndërtuar variablat e hyrjes dhe daljes bëjmë simui limin në Matlab [5].

Përgjigjia për këtë rast paraqitet si në figurën e mëposhtme:

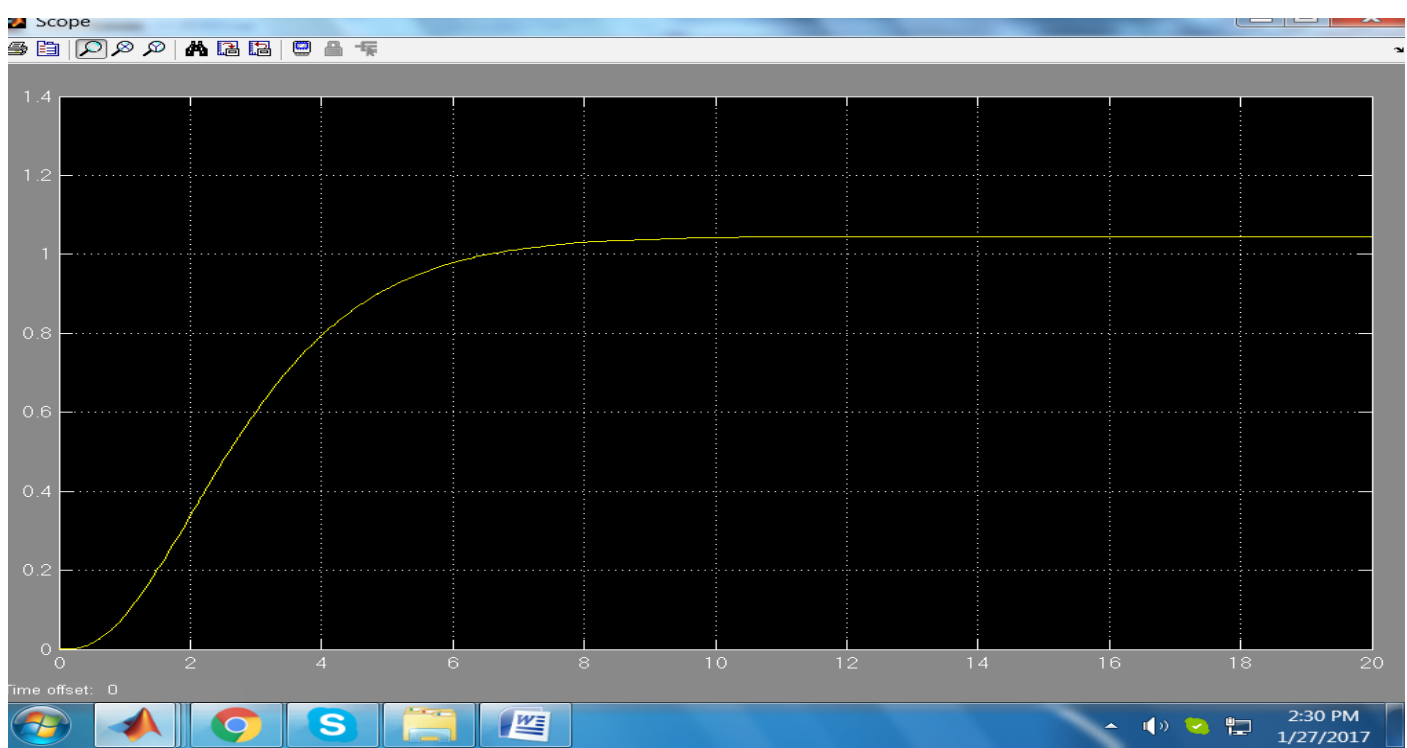

Figura 13:Përgjigjia kalimtare e sistemit duke përdorur logjikën Fuzzy

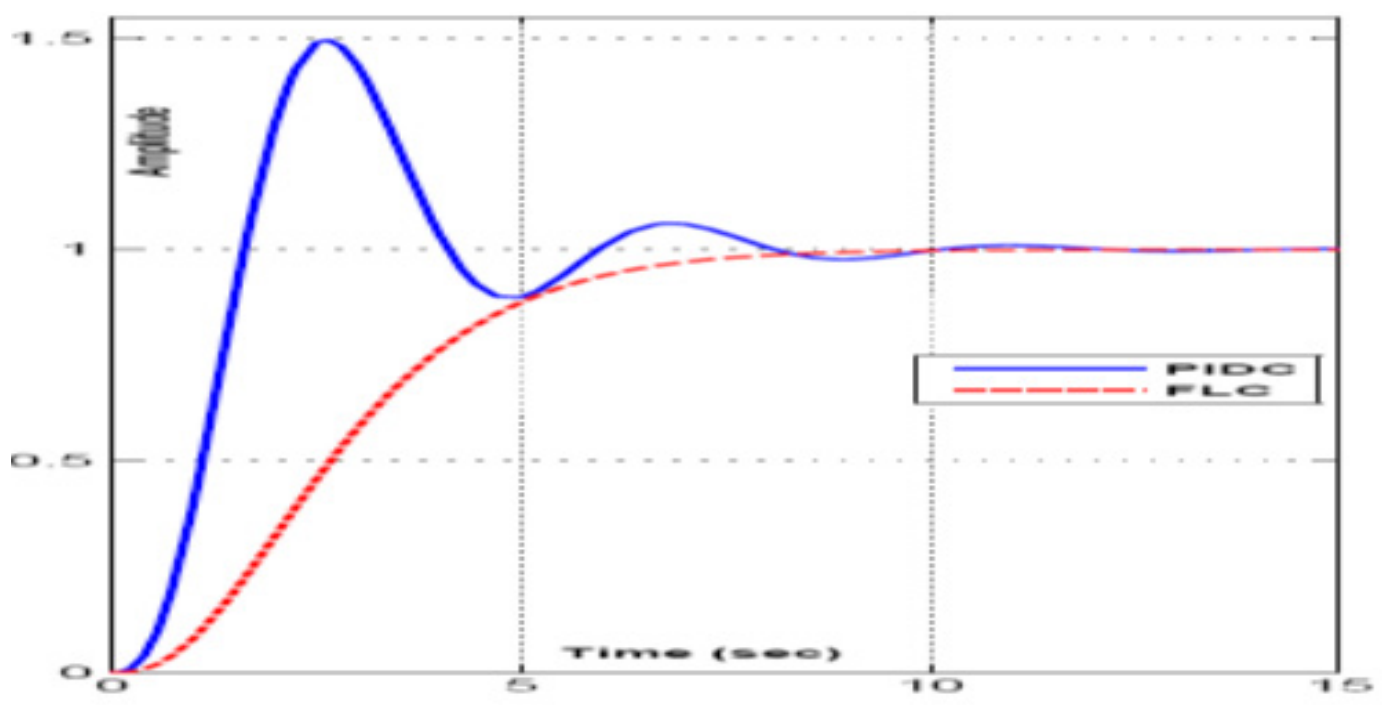

Figura 14: Përgjigjet kalimtare për dy rregullatoret 
Jozef Kola, Serxho Langa

Nga karakteristikat kemi nxjerrë parametrat e cilwsisë për secilën karakteristikë dhe bëjmë krahasim midis tyre [5].

Tabela 1:Krahasimi i rezultateve të arritura

\begin{tabular}{|c|c|c|}
\hline \multicolumn{3}{|c|}{ Parametrat e cilësisë } \\
\hline & $\mathrm{Mp}(\%)$ & $\mathrm{T}_{\mathrm{s}}(\mathrm{sec})$ \\
\hline PID & 49.24 & 8.83 \\
\hline FLC & 0 & 7.5 \\
\hline
\end{tabular}

Duke u nisur nga rezultatet e simulimit për modelin e aplikuar, vërejmë një rritje të lartë të performancave të përgjigjes kalimtare të sistemit në rastet kur do të zbatohet secili nga rregullatorët fuzzy të propozuar.

Implementimi i tij do të ishte në interes të ndryshimit të parametrave të cilësisë.

Rregullatori i propozuar ka treguar shumë qartë se është më i sukseshëm në ballafaqimin me gabimin dhe mënyrën e shpërndarjes së tij, duke treguar avantazhet e larta në krahasim me rregullatorin PID.

Nga krahasimi i rregullatorëve vërejmë këto përparësi të rregullatorit Fuzzy:

○ zvogëlohet shumë koha e ngritjes $T_{n}$ e lakores kalimtare, dhe kjo do të thotë arritje e shpejtë e vlerave të komanduara, gjë që shkon në favor të kërkesave për punime me shpejtësi të lartë,

- saktësia e punimit dhe rritja e produktivitetit po ashtu edhe mbirregullimi $\mathrm{M}_{\mathrm{p}}$ bëhet zero. Kjo për një proces industrial është shumë e rëndësishme [5].

\section{Përfundime}

Kontrollori PID është projektuar duke përdorur tekniken ZN, e cila përdoret për kontrollin e proceseve të rendit më të lartë. Krahas PID, është programuar rregullatori Fuzzy me një grup rregullash më të thjeshta dhe është prezantuar për të njëjtin proces. Performanca e tyre jepet duke i krahasuar njëri me tjetrin.

Në përmbledhje, mund të konkludojmë se, teknika ZN është një nga procedurat e akordimit të rregullatorëve PID për kontroll më të lartë të procesit, por FLC jep përgjigje më të mirë. Rregullatori PID, duke përdorur metodën ZN, jep mbirregullim të lartë dhe kohë stabilizimi të lartë, ndërsa FLC jep mbirregullim zero, dhe koha e stabilizimit është më e ulët në krahasim me kohën e stabilizmit të PID. 
PROJEKTIMI I LOGJIKËS FUZZY DHE RREGULLATORIT PID NË PROCESET INDUSTRIALE

\section{Referenca}

1. L. London, Disertacion përmbrojtjen e gradws shkencore, "Vlerësimi i gjendjes së transformatorve mbi bazën e gazeve të tretura në vaj dhe interpretimi me ndihmën e logjikës fuzzy”, Tetor 2015.

2. F. Idrizi, Punim Doktorature, "Optimizimi i rrugës së instrumentit me teknikat të inteligjencës artificial te makina frezuese vertikale me CNC", Korrik 2012.

3. S. Das, I. Pan, S. Das, "Performance Comparison of Optimal Fractional Order Hybrid Fuzzy PID Controllers for Handling Oscillatory Fractional Order Processes with Dead Time”, ISA transactions, Volume 52, Issue 4, July 2013, Pages 550-566.

4. https://www.massey.ac.nz/ nhreyes/MASSEY/159741/Lectures/Lec2012-3-159741FuzzyLogic-v.2.pdf

5. J. Zhang, N. Wang and S. Wang, "A developed method of tuning PID controllers with fuzzy rules for integrating process", Proceedings of the American Control Conference, Boston, (2004) 1109-1114. 